\title{
Polarity and Polarisability of 3,3-Dimethyl-1-phosphabutyne
}

E.A.Ishmaeva, I.I.Patsanoveky, J.z.Stepanova,

G.Becker, R.Knebl, U.Weeber and A.N.Pudovik

Kazan State Univeraity, 420008, Kazan, USSR

Institut $f$. Anorganische Chemie, Universität Stuttgart, FRG

The progress attained in the field of onecoordinated phosphomus compounds was summerised recently in review (Usp.ChIm.,1985, v.54, p.418). Formerly we have been analyeed (Izv.Akad.Nauk USSR, Ser.chim., 1984, p.415) the polarity of PEC triple bond in phosphaalkynes on the grounds of literary date on dipole momente defined by microwave spectroscopy. In this work the dipole moment of 3,3-dimethyl-1-phosphabutyne (I) was determined in cyclohexane solution: $\mu_{\mathrm{exp}}=1,24 \pm 0,05 \mathrm{D}, \alpha=1,250, \gamma=0,078, \mathrm{P}_{0}=31,876 \mathrm{~cm}^{3}$. Analysis of all known up to date experimental date on polarity of phosphaalkynes brings us to the conclusion about small polarity of PSC triple bond and slight sensitivity of this value $(0,7$ $\pm 0,2 D$ towards carbon atom) to vareing of substituent at $C_{s p}$-atom. We can only note alight tendency of the increasing $m(P \equiv C)$ in the phosphaalkynes $\mathrm{RC}=\mathrm{P}\left(\mathrm{F}=\mathrm{H}, \mathrm{CH}_{3}, \mathrm{~F}, \mathrm{CH}=\mathrm{CH}_{2}, \mathrm{CN}, \mathrm{t}_{\mathrm{Bu}}\right)$ with the growth of $-I$ - effect of substituent $R$.

Onecoordinated phosphorus compounds have not been investigated previously by means of Kerr effect, an anfsotropy of polarizability of PEC bond was unknown. We determined experimental molar Kerr constant (I) in cyclohexane solution (104.10-12 e.s.u.). Molecular anisotropy of polarizability $\left(5,30 \mathrm{~A}^{3}\right)$ of (I) is determined mainly by anlootropy of PEC bond $\left(5,31 A^{3}\right)$. 